\title{
Administrative Reform: Forever a Work in Progress
}

\author{
Lorenda A. Naylor and David H. Rosenbloom \\ American University
}

The symposium began by posing ten major questions about contemporary administrative reform. The questions were gleaned from a broad literature on New Public Management (NPM) reforms. Logically, they should be considered before reform efforts are designed and implemented. Historically, however, administrative reform has not always been governed by logic (Caiden, 1991). How central or useful are the reforms adopted in Taiwan, China, Malaysia, Britain, Korea, Singapore, and Japan? This postscript provides some answers.

\section{Ten Questions: Some Answers}

Table 1 presents a "box score" of the conclusions the preceding studies reached with regard to the ten questions. Not every study addressed each one individually. However, there are some broad answers.

1. Problem definition. Each of the countries engaged in problem definition. Although there was considerable overlap in what the seven nations expected to achieve with NPM reforms, there were also some variations, mainly in emphasis. Taiwan viewed reform as an appropriate response to globalization, administrative corruption, and its desire to democratize by removing authoritarian structures. China and Singapore also considered NPM an appropriate administrative response to globalization. Along with Malaysia, Korea, and Japan, they emphasized the expected economic benefits of reforming their public services. Britain's reforms were heavily driven by politics and ideology, which favored privatization and the adoption of private sector business methods and incentives.

2. Quality of diagnosis. All seven countries diagnosed the barriers to better administrative performance. Again, there were variations in emphasis. In Britain, the national administrative structure and culture, which had evolved more or less continuously since the mid-1800s, was viewed as a chief problem. Malaysia and Singapore also emphasized the need for structural change. Taiwan considered an authoritarian history and corruption to be impediments to administrative modernization. Korea sought systematic changes in its public personnel system and methods of administrative operation. In Japan, bu-

The Journal of Comparative Asian Development, Vol. 1, No. 1 (Spring 2002)

(C) Copyright 2002 by Imprint Publications, Inc. All rights reserved. 


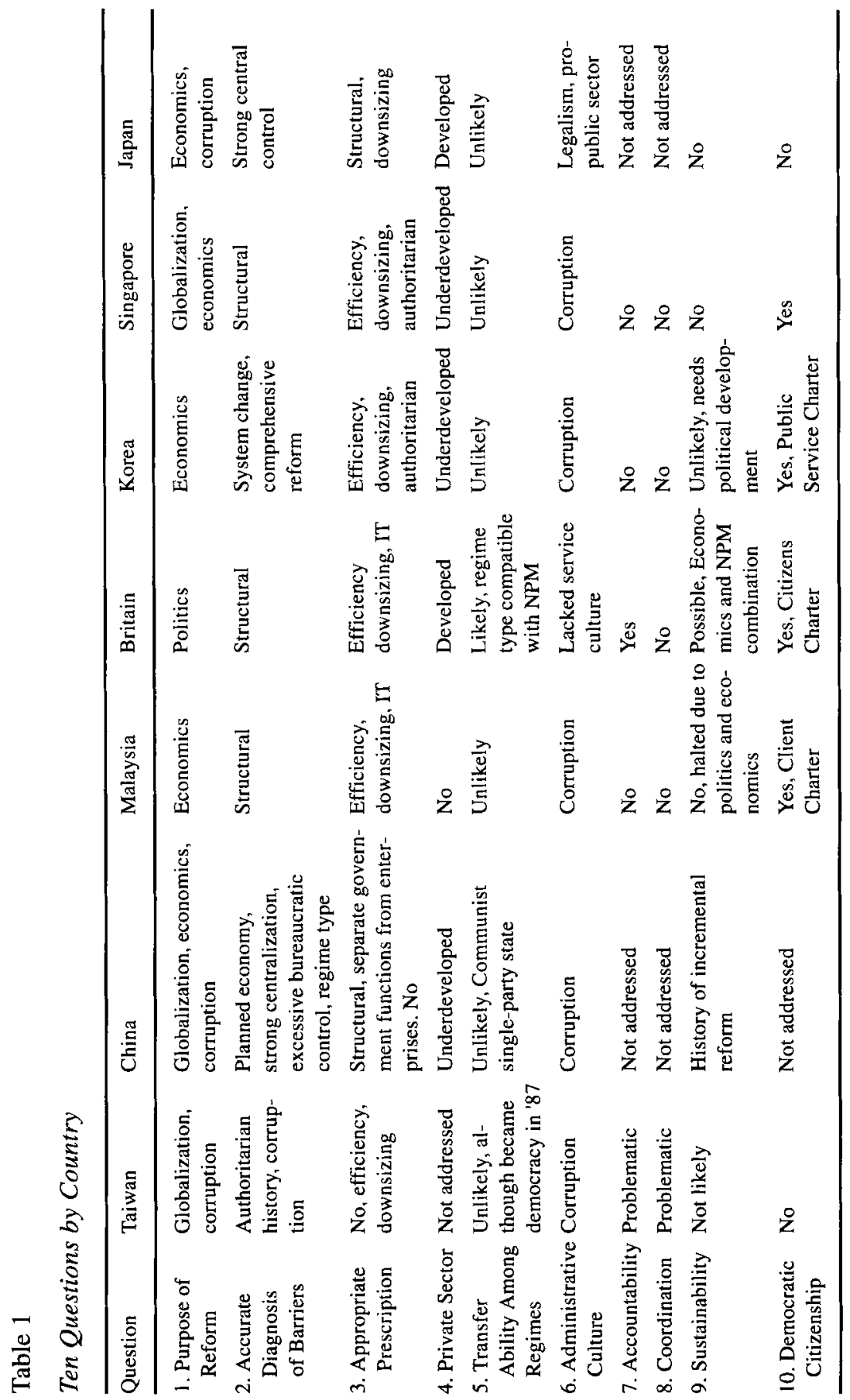


reaucratic power and over-control of the economy and local government were identified as the major challenges to better administration. China attributed unsatisfactory administrative performance to centralization and excessive bureaucratic control of a planned economy.

3. Appropriate prescription. Administrative downsizing, consolidation, and more business-like methods were the most common prescriptions. These fit the diagnosis in most countries. However, that prescription was inappropriate for Taiwan, in which there was a particularly great need to adjust an authoritarian administrative tradition to democratization and to define more fully the relationship between democratic governance and public administration. In addition to downsizing, China sought major structural reforms, including greater autonomy for state enterprises.

4. Private sector capacity to support reform. Private sector capacity in the seven nations varies substantially. Japan and Britain are among world leaders in private sector capacity. The private sector in Korea is hampered by inadequate modernization. Malaysia and Singapore are models of state-led economic development and growth, in which autonomous private sector capacity appears to be uncertain. China is in the process of developing a more marketized economy. Britain was perhaps most successful in relying on the privatization to improve governmental performance.

5. NPM's transferability across regimes. Great Britain pioneered NPM. It is a longstanding, stable parliamentary democracy, with a strong legal system and a political culture that supports broad civil rights and liberties. It was able to use NPM reforms for structural change in government without jeopardizing institutionalized political arrangements. It did not face the issues that NPM poses for presidential systems, in which executive and legislative power are separated rather than fused. NPM was not easily transferable to the other six countries. This is perhaps the most important finding of the symposium as a whole. Taiwan had trouble absorbing NPM because it first needed to strengthen and better define its democracy. Nor does NPM appear suitable for Malaysia and Singapore, in which the state did much of the "rowing" as well as the steering in spurring economic development and public governance. In Japan, NPM reforms have been unable to penetrate a political system and administrative culture in which bureaucratic power is deeply entrenched. There, NPM is largely a thin veneer on a system of stable power relationships. NPM is a mismatch for Chinese economic organization. It assumes a market economy so that government does not have to row and customers know what service is and how to demand it. China's market initiatives still lag behind NPM prerequisites. NPM's suitability for Korea is more mixed. It's success will depend on presidential commitment over the long term. The Korean case also illustrates that timing with regard to economic performance is important. Government downsizing during recession causes greater unemployment, with attendant social problems and potential political ones. Public sector downsizing does not move the problem to another sector, it shifts it within government. 
6. Transferability among administrative cultures. Here, too, it appears that NPM is more suitable for Britain than any of the other countries studied. If British administrators did not embrace NPM, they accepted it. Their previous lack of customer orientation was not an attribute of social status, manifestation of power, or key feature of the nation's administrative culture. Nor was there a culture of corruption. Korea's administrative culture still supports a fair amount of corruption, paternalism, hierarchical authoritarianism, and centralized control-all of which run counter to NPM requirements for customer service, employee empowerment, decentralization, and disaggregation. Corruption and an authoritarian legacy pose problems for Taiwan. In China, decentralization apparently invites corruption. Japan's bureaucratic power elite are resisting downsizing and decentralization. Malaysia and Singapore embrace customer service. However, NPM's fit with regard to public sector integrity and public-private partnerships bears watching.

7. Accountability. All seven countries face accountability problems. The British rely heavily on performance indicators, but the proliferation of quangos poses something of a problem. Privatization is not generally subject to the transparency requirements that partly define the government. NPM does not appear to enhance administrative accountability in Taiwan, China, Malaysia, Korea, Singapore, or Japan. Its impact may be negative in Malaysia and Singapore. Although not emphasized precisely in the country studies, with the possible exception of Britain, none seems to have a strong capacity for monitoring contractors or the relationships between nongovernmental providers of public services and the public.

8. Coordination. The extent to which administration reformed along NPM lines can be coordinated remains an open question. Britain is the obvious test case, and it requires more analysis. A "hollow state" or "disarticulated" state may have to be recentralized. Unlike an economic market in which there is a profit motive, any hidden hand associated with customer demand for administrative services may hide more than it guides. None of the country studies identifies a solution to the problem of coordinating decentralized, customerdriven agencies staffed by empowered employees.

9. Sustainability. NPM appears to be sustainable in Britain, Japan, and possibly, Korea, though for very different reasons. In Britain, a corner has been turned on privatization and customer service. Either can dwindle, but neither is likely to be consciously reversed through concerted governmental effort. In Japan, NPM terminology and concepts may be sustainable precisely because they make little difference. Implementation has been weak and the bureaucratic elite has been able to divert and defuse NPM's threats to their status and power. If Korea remains on its present path, it may build a sustainable NPM-based public service. Its success will depend largely on continuing presidential commitment and economic growth. Sustainability in Malaysia and Singapore may well be defined by economic conditions and the extent to which political leaders support disarticulation of the state, which has been so central in both multi-ethnic nations. NPM is not the correct prescription for Taiwan's 
administrative problems and presumably will not last there. As in Japan, if NPM continues to affect Chinese reform it will be because it does not change the distribution of political and administrative power in any fundamental fashion.

10. Democratic citizenship. NPM intentionally weakens overhead democratic control of public administration. It substitutes customer demand for citizen input and focuses accountability on performance rather than procedural regularity. Consequently, it can fragment public opinion, weaken civic life, and reduce the public's role in defining public values through the election of legislators and other officials.

Britain clearly recognizes this, and has tried to combat it with the "People's Panel" and other means of gaining focused public input. These may work in a stable democracy and strong democratic culture. In Taiwan, Malaysia, and Singapore, NPM seems largely irrelevant to democratization at best. At worst, it may detract from it through privatization, encouragement of self-interested customer behavior, and the diminution of the state as a vehicle for pursuing public values and policy goals in a coordinated fashion. Corruption in privatizing would also undermine governmental prestige and authority. Korea may also face some of these potential threats, but probably on a smaller scale. NPM is largely irrelevant to democratic citizenship in Japan, where NPM has not been implemented, and China, which, of course, is not a democracy.

\section{Conclusion}

The symposium offers a great deal of new insight and perspective on NPM. It shows that NPM is essentially a flexible set of concepts which can be adopted and adapted for different purposes in different settings. It is not a rigid, offthe-shelf blueprint for administrative reform. The NPM label belies the variation that occurs under it. Britain and Japan both have highly developed economies and both are democracies. Yet their experience with NPM reforms has been almost totally different. The symposium confirms Caiden's (1991) observation that: "If anything has been learnt from reform experiences, it is not to expect instant miracles; progress in administrative reform is gradual, selective and piecemeal; attempts to hasten the pace or cover everything rarely succeed. Administrative reform is only a part, admittedly an increasingly crucial part, of the much greater enterprise of institutional reform ..." (p. 10).

NPM is a step, not a solution. Even where it solves one set of problems, it may cause others. Britain has had considerable success with NPM, but has not found the key to overall coordination and democratic accountability. Administrative reform tends to move the problem. As long as countries seek to improve their administration, reform will be forever a work in progress. 